Laura Moutinho

Universidade Federal do Rio de J aneiro

\title{
Negociando com a adversidade: reflexões sobre "raça", (homos)sexualidade e desigualdade social no Rio de Janeiro
}

\begin{abstract}
Resumo: 0 objetivo deste artigo é disc utir como a dinâ mic a dos a fetos e prazeres se cruza com a desigualdade social no circ uito GLS carioca. Ma is especific a mente, será abordada parte da trajetória de vida de dois jovens homossexuais negros que vivem no subúrbio carioca e de um que vive na favela da Maré. 0 trabalho de campo evidenciou que nesse contexto os homossexuais masc ulinos mais esc uros que moram nos subúrbiose nas favelas do Rio de J a neiro possuem um campo de manobra mais amplo do que aqueles nos quais se inserem rapazes e moças heterossexuais da região e, mesmo, as lésbic as e travestis de diferentes cores que habitam essas áreas.
\end{abstract}

Palavras-chave: homossexua lidade, pobreza, raça/c or, Rio de J aneiro, relações a fetivo-sexuais inter-racia is, desigualda de social.

\author{
Copyright $\odot 2006$ by Revista \\ Estudos Feministas \\ ${ }^{1}$ SILVA e HASENBALG, 1992. \\ 2 SILVA e HASENBALG, 1992, p. 3. \\ 3 "Heteroc rômic os" é uma catego- \\ ria que Tha les de AZEVEDO, 1975, \\ utiliza ao se referir aos relaciona- \\ mentos a fetivo-sexua is entre \\ brancos e negros. Sua lógic a \\ argumentativa se aproxima da \\ clássica oposição sistematiza da \\ por Oracy NOGUEIRA, 1985, a \\ respeito dasculturasque operam \\ preponderantemente com a \\ aparência (como o Brasil) e as \\ que enfatizam a ascendência \\ como critério de classificação
}

\section{Introdução}

Como lembram Nelson do Valle e Silva e Carlos Ha senbalg, ${ }^{1}$ em inúmeras a nálises sociológicas o casamento inter-racial e a miscigenação foram classifica dos como a "prova do ácido" das relações racia is no Brasil. Os autores explicam com clareza esse ponto:

$$
\begin{aligned}
& \text { é no momento de constituição da família, núcleo básico } \\
& \text { da estratific ação social, que as marcas ma is } \\
& \text { fundamentais das distâncias que regulam a convivência } \\
& \text { dos grupos de cor devem ser observadas. }{ }^{2}
\end{aligned}
$$

Na pesquisa que realizei para o doutoramento focalizei esse e outros temas correla tos a o analisar os relacionamentos a fetivo-sexua is heterocrômicos ${ }^{3}$ entre 
racial (no caso, os Estados Unidos). A análise de Thales de Azevedo, entretanto, traz uma diferença importante em relação ao trabalho de Oracy Nogueira. De acordo com o primeiro autor o modo de classificação de cor (em contraposição ao de raça) compreende critérios de ordem estética. Trata-se de uma diferença de teminologia que, todavia, permite que se enfatize o lugare importância dos a tributos de prestíg io na construção social da cor. A a parência soa como algo dado, enquanto a estética pode ser construída e manipulada de diferentes maneiras.

${ }^{4}$ Ver detalhes em MOUTINHO, 2004.

${ }^{5}$ Essa pesquisa integrou o "Projeto Recém-Doutor" que desenvolv no âmbito do Instituto de Medicina Social (IMS) e do Centro LatinoAmeric a no em Sexualidade Direitos Humanos (CLAM). A pesquisa foi apoiada inicialmente pelo CNPq e a tualmente faz parte do "Projeto Integrado Sexualidade, Gênero e Família: rupturas e continuidades na experiência da pessoa ocidental modema", coordenado por Luiz Femando Dia Duarte (PPGAS/MN/UFRJ) e Jane Russo (CLAM/IMS/UERJ). Recebeu subsídios da FAPERI, através da bolsa de Fixação de Pesquisado e do "Programa Cientista Jovem do Nosso Esta do - FAPERJ/2003". Nessa parte do trabalho, contei com o apoio fundamental de Crystiane Castro, estudante de ciências sociais da UERJ. Fazem parte da equipe de pesquisa: Silvia Aguião (pesquisando a favela de Rio das Pedras), Vítor Grunvald (que pesquisou na Internet e nos chats homossexuais) e Débora Baldelli (festas/boates de música eletrônica da zona su carioca).

${ }^{6}$ Sigla referente a Gays, Lésbicas e Simpatizantes (ou suspeitos, como se diz em tom jocoso).

7 Sobre o entrecruzamento entre raça, gênero e violência na favela de Rio das Pedras, cf. MOUTINHO 2002. Ver também sobre o tema Marcos ALVITO, 2001, e Alba ZALUAR, 1994 c asa is heterossexua is no Brasil e na Áfric a do Sul. ${ }^{4}$ Entreta nto, novos conto mos podem ser observa dos sobre essa temática se volta rmos o olharpara as parc eria s heteroc rômic a s entre homossexuais. Assim, o que se pretende nas páginas que se seguem é a mpliara a nálise a nterior seguindo a tra jetória de jovens homossexua is negros que vivem em situação de pobreza no Rio de Janeiro.

Nesse sentido, irei a presentar e discutir parte do trabalho de campo da pesquisa que coordenei sobre os relacionamentos a fetivo-sexua is inter-racia is entre gays na cidade do Rio de Janeiro. ${ }^{5}$ Será apresentado o trânsito possível que o circuito GLS $^{6}$ possibilita e, mais especificamente, como a dinâmica dos afetos e prazeres se cruza com a desigualda de social nesse contexto.

\section{O desenho da pesquisa}

Durante cerca de três a nos entrevistei e convivi com gays e lésbicas que moravam nas favelas da Maré e Rio das Pedras, ${ }^{7}$ em bairros do subúrbio e da zona sul, e que tivessem mantido um ou mais relacionamentos afetivossexua is heteroc rômic os. 0 traba lho de campo consistiu em entrevistas no forma to história de vida ${ }^{8}$ quando se procurou registrar tanto a trajetória afetivo-sexual dos entrevistados quanto as experiências religiosas, escolares, no mercado de trabalho, bem como os cálculos que cada um fazcom relação à prevenção às DSTS/AIDS. Além disso, percorri candomblés, boates, eventos esportivos ou qualquer situação de lazer para a qual tivesse sido convidada a participar e que fosse propiciadora e facilitadora de encontros amorosos e sexuais.

Como na pesquisa realizada para o doutoramento, trabalhei com a autoclassificação de cor/raça e de orientação sexual fornecida pelos próprios entrevistados. Ta mbém nesse contexto essa é uma questão delic ada. Tive o cuidado de me aproximar somente daqueles que a própria rede de sociabilida de definia que compunham um casal inter-racial e somente entrevistei um dos pares, pois na experiência anterior de pesquisa a entrevista com o casal se revelou como um espaço propício a que tensões da díade envolvessem a pesquisa dora e comprometessem o trabalho. O terreno das identidades de gênero, da orientação e das experiências sexuais é igualmente pantanoso. Nesse sentido, trabalhei sempre com as c a teg o rias c la ssific a tória s dos próp rios entrevista dos.

As fo foc as sexua is compõem um importante espa ço da pesquisa, sobretudo, no caso dos jovens homossexua is do candomblé. Aconteceu algumas vezes de, após uma entrevista ou depois de uma animada conversa com o 
${ }^{8}$ A noção de história de vida e, mais especific a mente, os a contecimentos biográficos foram compreendidos como coloca ções e deslocamentos possíveis no interior do espaço social. Como a firma Pierre Bourdieu, "como estados sucessivos da estrutura de distribuição de diferentes espécies de capitais em jogo no campo". No caso específico dessa pesquisa, dos afetos e prazeres masculinos e femininos de matizes inter-racia is (BOURDIEU, 1996, p. 190).

${ }^{9}$ Forma como são chamados os homens iniciados que não entram em transe. Diferentemente dos adés, a performance dos ogãs é viril e seu desejo sexual se dirige a meninas e não meninos como no caso dosadés. ${ }^{10}$ DOUG LAS, 1966.

${ }^{11}$ Cf. Peter FRY, 1982; Maria Lina TEIXEIRA, 1986; Patrícia BIRMAN

1995 , entre outros

12 PERLONG HER, 1987

${ }^{13}$ BIRMAN, 1997.

${ }^{14}$ PERLONG HER, 1987, p. 144. grupo sobre sexo e paqueras, serpuxada para um canto e ouvir aos sussurros que o que "fulano" falou não é bem assim e que, na verdade, ele gosta de... e a conversa enveredava para detalhes picantes, sempre em tom de riso e galhofa, sobre um ou ma is membros do grupo. Esse tipo de rumor, ainda que disseminado e presente nas conversas, como, aliás, a freqüente desconfiança com relação à performance viril dos ogã $s,{ }^{9}$ nã o foi a presentado como possuindo um caráter poluidor, no sentido que the empresta Mary Douglas, ${ }^{10}$ mas como parte de um jogo lúdico que não oferece exatamente perigo de perda de prestígio ou posição. Importante destacar, nesse sentido, que as fofocase as relações jocosas não são diretamente despertadas pelo tema investigado. Elas fazem parte do universo mais amplo da pesquisa e, como vários autores destacaram, esse segmento religioso tem como marca as rivalida dese fofocas, disputa se ironias, ou seja, a quilo que a literatura destaca como "xoxação".11

Néstor Perlongher e Patrícia Birman ${ }^{13}$ chamaram a atenção, inclusive, para a forma como a linguagem do santo percorre diferencia dos domínios, nã o se restring ind o a o universo dos cultos de possessão. No gueto paulistano, por exemplo, essa relação com o mundo mágico e sobrena tural funcionava como sinal de respeito e proteção para com osma land ros e mic hês do loc al. ${ }^{14}$ Situa ção similar pôde ser identificada na pesquisa atual no subúrbio e na favela da Maré, não se fazendo presente, entretanto, nas festas undergrounds da zona sul carioca.

Faz-se necessário destacar ainda que as regiões pesquisadas são marcadas de modo diferenciado pela violência e pelo tráfico de drogas. As favelas da Ma ré e de Rio das Pedras - a primeira localiza da em subúrbio do Rio de Janeiro e a segunda na zona oeste, próxima à Barra da Tijuca - são paradigmáticas dos estudos de violência. A favela da Maré é conhecida na mídia carioca e nacional pela violência entre traficantes ou entre eles e a polícia. A favela de Rio das Pedras é nacional e intemacionalmente reconhecida pela "não-violência", em especiala violência que costuma ser associada a o tráfic o - embora sejam recorrentes os rumores a respeito da ação da "polícia mineira", um tipo de poder paralelo que trabalharia não somente no sentido de manter a ordem mas também de coibir o tráfico e o uso de drogas ilícitas no local.

A parte do subúrbio carioca onde a pesquisa foi realizada fica próxima de regiões violentas, mas os moradores vivem em relativa tranqüilidade, sem medo direto das guerras do tráfico nem de balas perdidas. Esse é um aspecto importante, pois, na primeira pesquisa que realizei em Rio das Pedras, a relação entre gênero, 
15 Sobre o tema, ver, entre outros tra balhosda a utora, ZALUAR, 2004 Sobre estilos de masculinida de em diferentes camadas sociais, ver Fátima CEC CHEITIO, 2004

${ }^{16}$ ALVITO, 2001

${ }^{17}$ Cf. MOUTINHO, 2002

18 Sobre o tema ver BALDELL e MOUTINHO, 2004.

${ }^{19}$ Cf. MOUTNHO, 2005.

${ }^{20}$ VELHO, 1994

21 A despeito do visível crescimento dasigrejas sevangélicas, os candomblés se mantêm - de modo particularmente visível nos subúrbios e nas favelas cariocas - como um espaco fundamental não somente de vivência e expressão da religiosidade, mas, igualmente, de sociabilidade, lazere encontros a morosos. Sobre homossexualidade no candomblé, ver BIRMAN, 1995 e 1997, e FRY, 1982. sexualidade e violência se explicitou na identificação de um ethos viril cavalheiresco, em oposição, por exemplo, ao que Zaluar nomeou de ethos guerreiro, presente no tráfico de drogas ${ }^{15}$ e também registrado por Alvito ${ }^{16}$ em Acari. Em Rio das Pedras reg istra-se uma estrutura de poder, um prestígio e um código de honra fundamentalmente diferentes daqueles encontrados em favelas com forte tráfic o de drogas. Nesse sentido, foi objetivo dessa pesquisa analisar o lugar da homossexualidade e da raça nesse contexto, e mais especificamente compreender de que forma a violência ca rac terístic a dessa s regiões não somente influenciava a relação entre os gêneros, bem como as diferentes orientações sexua is e de raça. Como procurei demonstrar em outro trabalho, ${ }^{17}$ o idioma de gênero, raça e sexua lida de dominante e sua a rtic ula çã o com violência e o tráfico de drogas são elementos de fundamental importância para a compreensão da dinâmica dos relac iona mentos a fetivo-sexua is inter-racia is entre parc erias gays e lésbicas dessas regiões.

$\mathrm{Na} z o n a$ sul carioca a pesquisa foi realizada fundamentalmente em algumas boates e festas que são associadas a o público GLS - como as boates Dama de Ferro, Galeria Café, Fosfobox e 00 (Zero Zero), e as festas XDemente e B.I.TC.H (Barbies in Total Control Here). Todas essas festas e boates possuem ao menos uma noite (ou pista) dedicada ao som de House e Electro, eleitos como os gêneros de música de preferência daqueles que partic ipam desse circ uito. ${ }^{18}$

No presente artigo, irei explorar mais especificamente parte da trajetória de vida de dois jovens homossexua is negros que vivem no subúrbio carioca e de um que vive na favela da Maré. Nesse contexto, tem sido interessante notar, como destaquei anteriormente, ${ }^{19}$ como os homossexua is masculinos ma is esc uros que moram nos subúrbios e nas favelas do Rio de Janeiro possuem um "campo de possibilidades", nos termos de Gilberto Velho, 20 ma is a mplo do que de rapazes e moças heterossexua is $d a$ região e mesmo, até onde o trabalho de campo permite afirmar, de lésbicas e travestis que habitam essas áreas. Para os homens gays ma is esc uros, em especial, é possível perc orrer e ultra passar, de diferentes modose com distintas interações, as linhas de classe do Rio de Janeiro, como será visto adiante.

No subúrbio do Rio de Janeiro, a maioria dos entrevistados divide a maior parte de seu tempo entre percorreros candomblés, ${ }^{21}$ esc olas de samba e boates da região. Mas não apenas. Ir às boates da zona sul, à praia de Copacabana e ao bairro da Lapa são programasque eles fazem com alguma regularidade. Às vezes vão para 
22 Sobre envelhecimento e homossexualidade, ver Julio SIMÕES, 2004. "zoar" e paquerar, outras vezes para "fazer dinheiro", como a firma ram a lguns entrevistados.

Algumas das experiências de pesquisa me tocaram profundamente. Dentre as escolhas que poderia ter feito, selecionei para apresentar três situa ções profundamente ilustrativas desse campo que cruza raça, (homos)sexualidade, desigualdade social e, de modo variado, a violência. Vejamos a seguir.

\section{Uma expressão do desamparo público no subúrbio carioca}

Mateus tem uma trajetória dramática e paradigmática. "Bicha alegre" e "caricata", como denunciou um amigo; "preto mesmo" ou "moreno escuro", como ele diz, "pois, deu seis horas, é noite, né?!". 16 anos. Filho de um traficante que morreu antes mesmo de ele nascer... "de engano", como explicou. Na fa vela de Vigário Geral, há 17 anos, "eles" mataram o pai de Mateus achando que ele fosse outra pessoa. Sua mãe está no terceiro casamento e seu padrasto anterior, também "da coisa", morreu assa ssina do.

Mateussempre morou no ba irro de Parada de Lucas, perto de Brás de Pina, subúrbio d o Rio de J a neiro. Dedic ouse por algum tempo à dança e hoje faz supletivo, como muitos jovens da região, para compensar consecutivos abandonos escolares. Sobre sua trajetória escolar, disseme com orgulho: "Nunca fiquei reprovado, sabe?". Ele fazia dança em uma escola pública e me mostrou várias fotos dassuasapresentações. No momento da entrevista, Mateus não estava matriculado em nenhum curso. Perguntei-lhe se não havia na região nenhum local onde ele pudesse dançar ou fazer algum outro curso que fosse do seu interesse. Ele me disse que tinha algumas noções de informática, adquiridas em um curso rápido que fez em uma Igreja Batista da redondeza, e que chegou a irà fa vela da Maré para tentaringressarno Corpo de Dança da Maré, masachou perigoso ficarentrando na "comunidade": tinha medo de ser "confundido" como seu pai e desistiu.

Ele se disse paquerado. Disse que sabe que homens de diferentes idades gostam dele porque ele é jovem e que procura aproveitarisso. Mateus não gosta de homens $\mathrm{da}$ idade dele. Prefere os homens ma is velhos. Interessante notarque os "mais velhos" compõem uma a mpla faixa que vai desde osrapazes de 22 a nosa té os "coroas", com cerca de 60 anos. $^{22}$ Mateus gosta de paquerar na praia de Copacabana e se classific ou como "nervosinho" no terreno das interações amorosas: "Hoje estou com um, mas vejo um ali no meio e já...", a firmou às gargalhadas. 
No trabalho de campo, identifiquei a té o momento duas grandes linhas de atuação de jovens homossexua is masculinos, e em especial negros, no circuito dos afetos e prazeres da zona sul carioca: aqueles que vão a Copacabana, preferencialmente à boate Le Boy, buscar gringos brancoscom interesse pecuniário ("pode-se ganhar a té 100 dólares em alguns minutos", disse-me outro entrevistado); e os que buscam gringos, brancos, mais velhos, na intenção de se divertir, mas, igualmente, de ter relações diversificadas e intensas. Voltarei a esse ponto, porém vale destacar que essas não são posturas excludentes.

Mateus afirmou que não gostava de namorar rapazes negros, mas teve uma "experiência boa, não foi ruim, daí eu tirei esse negócio da cabeça". Explicou da seguinte forma a situação: "Eu ia pela cabeça das pessoas, hoje em dia não, eu já estou bem crescido". Esse é um ponto importante, pois essa questão chegou a mim por pressão do grupo. Todos sabiam do tema de minha pesquisa e me empurravam Ma teus para provocaro rapaz a falar que não gostava de "sair com negros". o grupo sentia-se desconfortá vel com a forma como Mateus expressava suas preferências amorosas e eles pareciam querer constrangê-lo, expondo-o à pesquisa. Em verdade, a questão não era a preferência porparcerias inter-racia is (comum no grupo), mas a forma racista com que Mateusa exp ressava.

De fato, Mateus a firmou que existia m muitos casa is inter-ra cia is no culto de possessão que freqüenta, pois "o povo do candomblé está acostumado com preto". O convívio é a categoria-chave que explica por que o entrevistado não identifica situações de racismo no candomblé. Mateus sente fortemente a discriminação por ser "entendido": "às vezes você passa na rua, você nem mexe... Aí a gente tá passando, 'ah, viadinho', 'ah, vai marica, bichona', sei lá mais o quê... Já que não gostam, pra que mexer?", pergunta, entre o espanto e a mágoa.

Em resumo, como morador de uma região relativa mente tranqüila - a inda que próxima de fa velascom forte histórico de violência como, porexemplo, Vigário Geral e a própria favela de Parada de Lucas - Mateus padece da patente falta de ofertas e de iniciativas públicas e privadas naquela região. O candomblé aparece em sua na rrativa e em sua vida como uma das poucas ofertas de sociabilidade, troca, lazer e encontros. Vale destacar, por fim, que essa rede de contatos também propicia, eventualmente, acesso a algum tipo de emprego. Toda uma economia de trocase favoresajuda na sobrevivência. Foi possível notar nos discursos certa moralização da 
${ }^{23}$ ZALUAR, 2004, p. 20.

pobreza, com argumentos que evocavam o ócio e a falta de força de vontade dos indivíduos. Tra ta-se de uma rede horizontal de solidariedade, que evidencia a fragilidade de canais forma is de acesso à educação e ao emprego. Alba Zaluar chama a atenção para esse ponto quando discute a grande incidência de roubos e furtos em Madureira, que possui uma população jovem e empobrecida, como apontam os dados do IBGE para a região. Na interpretação da autora, a questão reside na "falta de regras" e no

conteúdo das novas regras que vão surgindo no vazio institucional que se forma a partir da sinergia entre a economia subterrânea, as organizações locais e as instituições supostamente enca rregadas de manter a lei e a ordem. ${ }^{23}$

Alguns entrevista dos trabalharam como garçom, motorista, entre outras ocupações que não exigem alta escolaridade. Um sonho comum desses jovens homossexuais? Alguns me confidenciaram: gostariam de se tomarcabeleireiros!

\section{Percorrendo os circuitos do desejo}

Saulo, um rapaz "negro", de 24 anos, morador do subúrbio, fazparte de um grupo de amigos - todos de santo - que circula pelos points do subúrbio e da zona oeste. Às vezes ele vai às boates Le Boy e Help, ambas em Copacabana, para "pegar" uns "gringos" e "fazer um trocado". Saulo afirmou que não trabalha. Deseja, como outros entrevistados, fazer curso de cabeleireiro e abandonou a escola antes de completaro Primeiro Grau. Ele não sabe bem explic aro porquê disso, acha que foram as "amizades", e coloca a questão da seguinte forma: "Comecei a sair demais, parei de estudar, mas estou voltando...", disse em tom evasivo.

Saulo não costuma namorar homens negros e também não sabe explicar sua preferência por homens brancos. Em sua opinião, "pa rece que um neg ro não gosta do outro. Acho que dentro deles deve existir algum preconceito, algum bloqueio, a lguma coisa. [...] eu já a té namorei um, entendeu? Mas outros, é muito difícil". Qua nto à idade, diz preferir homens ma is velhos, pois estes "têm mais coisa pra te passar. A pessoa nova é muito imatura".

Saulo faz sucesso entre homossexua is brancos e estrangeiros da zona sul ca rioca e entre os negros forâneos disse passar despercebido para os angolanos, pois "eles só querem branquinhos". Os mais bonitos para ele, entreta nto, são os neg ros norte-a meric a nos com quem já "saiu". É interessante notar como as noções de raça e cor 
${ }^{24}$ FERREIRA, 2005.

${ }^{25}$ Adria na PISC ITEய, 2004.

${ }^{26}$ BLANC HETIE e SILVA, 2004. entrecruzadas com nacionalida de compõem um quadro hierarquizado de ofertas sexuais no mercado do amor e do sexo em Copacabana. Alguns desses conta tos podem, inclusive, desdobrar-se em um vínculo ma is longo. Saulo aponta o negro a fric ano como o menos prestigiado nesse contexto.

Esse é um aspecto interessante. Marcelo Ferreira ${ }^{24}$ trabalha exatamente com o desconforto do mercado do turismo carioc a com negros norte-a meric a nos de alto poder a quisitivo, que somente circula m por loc a is "brancos". Nesse "turismo a fro-americano", com viés fortemente milita nte, as mulheres negras a parecem em um lugar central. Trata-se, de fa to, de um turismo ma is "fa mília", que tem como destino principal Rio de Janeiro e Salvador, cidades nas qua is a demanda porviver (e se a limentar) de um merca do étnic o/ racial é organizada pelas mulheres. A busca por "autenticidade"25 é uma categoria-chave nesse universo. No caso do chamado "turismo sexual", Ferreira notou que, a o invés de grandes grupos, esse viajante vem no máximo com três pessoas, com pouco interesse pelos pontos turísticos tradicionais e mesmo pela forma como se organizam as relações entre brancos, negros e mestiços no Brasil. Para esses viajantes, a "mistura" não aparece como um problema.

De acordo com Thaddeus Blanchette e Ana Paula Silva, ${ }^{26}$ que analisaram o mercado sexual (heterossexual) carioca, especialmente o que prevalece em Copacabana, o Rio de Janeiro funciona como um "campo de diversões sexua is" para estrangeiros por conta da desvaloriza ção do real diante do euro e do dólar; pela idéia de que, em relação a outros mercados como Ásia, África e Oriente Médio, o Rio de Janeiro seja tido como um espaço relativamente seguro e pelo fato de que o mercado do sexo conta com uma estrutura qua lific a da de orga niza ção, com termas e boates. Dentre os fatores perfilados pelos autores chama a atenção, embora não surpreenda, a crença na sensualidade particular da mulher brasileira. É significativa a percepção de que as garotas de programa se prostituem, mas "não agem como putas". Desse ponto, interessa-me reter a idéia de que a situação assim percebida facilitaria a transformação dos envolvimentos sexuais em afetivos, uma percepção que também se faz presente entre as garotas de programa.

Pisc itelli trabalha com um conceito de turismo sexual que auxilia na compreensão desse universo, que, como vem evidenciando meu trabalho de campo, não se restringe a o turismo heterossexual. Vejamos o que diz a autora: 
27 PISC ITEШ, 2001, p. 4.

${ }^{28}$ PISC ITEU, 2004. o turismo sexual é [...] qualquer experiência de viagem na quala prestação de serviços sexua is da população local em troca de retribuições monetárias e não monetárias seja um elemento crucial para a fruição da viagem. ${ }^{27}$

As trajetórias de Saulo e de outros rapazes negros gua rda $m$, inc lusive, semelhanç as interessantes com as das mulheres pesquisa das pela a utora. ${ }^{28} \mathrm{~A}$ trajetória de Marcos expressa o que estou tentand o enfatizar. Vejamos a seguir.

\section{Trocas e interações a morosas entre classes e cores distintas}

Marcos tinha pouco mais de 20 anos quando eu o entrevistei, fazia telecurso, nunca tinha tido namorado ou "fic a do" com uma mulher: "nunca nem beijei mulher", disse. Afirmou também que gosta muito de homem bonito, que freqüenta a Lapa, uma boate de Bangu, e algumas outras de Copacabana. Foi em uma delas que conheceu um namorado europeu, branco, com quem namorou por seis meses, chegando a morar com ele em Ipanema. Marcos contou que ele e vários de seus amigos negros vão para as boates da zona sul encontrar os gringos: "Tem muitos gaysque vêm para o Brasil e eles gostam muito de paquerar os negros". Segundo sua explicação, os gringos acham que os "negros têm mais calor, que têm uma coisa diferente". E para ele os gringos "são legais" porque "têm uma cultura diferente". Marcos não acha os gringos fisic a mente muito a traentes. Ele se "a trai" pelo "jeito de ser": "Ser pessoas de fora, de outro país". Disse ainda que "é legal ter contato com uma pessoa que me mostra coisas que eu só vejo na televisão". Marcos explic ou da seguinte forma esse tipo de encontro: "Trocar informação. Ele fala dele, como ele vive lá, e eu falo como vivo aqui. Então isso é muito interessante, é bem legal você explorarisso dele e ele explorarisso da gente".

Sexualmente ele diz que é "normal", mas que os gring os a cham que os negros são "fogorosos"! No merca do do amore do sexo Marcosconsidera que não tem chance com os brancos brasileiros, "porque eles dão preferência a o pessoal que é dali, da zona sul"; e que com os "gring os" isso não acontece. "Eles acabam dando preferência para a gente, principalmente por ser negro. Amigos meus, gays e brancos, dizem: 'Puxa! O que vocês têm? A gente fic a de escanteio'." Eu também não sei o que é isso...", disse Marcos, gesticulando enfatic a mente de modo a expressar espanto e incerteza.

A perspectiva apresentada por Marcos é muito interessante, pois está todo o tempo falando em troca. 
${ }^{29}$ Cf. PERLONG HER, 1987.

30 Sobre o tema, cf. Verena STOLCKE, 1991.
Como no caso dos dema is entrevistados, trata-se de uma troca marcada pela desigualdade social, mas interessante para a mbas aspartes. Ele morou com o "gringo", ia a festas, conheceu gente de vários países: ele aprendeu e deu informações e ao mesmo tempo também as recebeu. Interessante, por exemplo, é que quase todos os dias ele volta va para a região onde reside para verosamigos, para matar saudade, como explic ou de maneira dispersa.

Sobre discrimina ção, ele me disse que é muito difícil ser negro e homossexual ("nenhuma família merece!"), e que onde mora é ma is complic a do sergay do que lésbica, pois a cha que elas são ma is respeitadas. Marcos sente-se muito discriminado, mas é "boyzinho" (quer dizer, veste-se como homem), e para ele o pior mesmo é ser "travesti". Disse que os homens nem conversam com "tra vesti", porque, se ele sentar com uma para conversar, vai todo mundo dizer que "ele está pegando um travesti, uma 'tra vola'", como elucidou.

Marcos disse que sentia a tração sexual por homens brancos, mas o outro motivo que o levava a não sair com negros se referia a "oportunidade". Sua fala possui eco com a de outros entrevistados e entrevistadas de diferentes classes e orientações sexuais: "Acho que um negro não gosta de outro negro", a firmou enfático.

\section{Desfecho}

Diferenças de gênero, de classe, ida de e, mesmo, de cor constituem categorias que funcionam como tensores libidina is que orientam os sujeitos na busca por corpose prazeres. ${ }^{29}$ Nesse sentido, a cornegra aparece marcada pelo erotismo e paira sob o universo erótico dos encontros amorosos - sejam eles homo ou heterossexua is.

Desde o início do trabalho de campo, venho notando uma não-diferenciação de alguns aspectos significativos em relação a certas representa ções socia is veiculadas pelos relacionamentos afetivo-sexuais heterocrômicos entre parcerias heterossexua is e gays masculinas. Vale destacar que, tanto nos arranjos heterocrômicos homossexuais quanto entre os heterossexuais, a raça/cornão evoca uma distinção moral. Caráter, por exemplo, é algo que se desenvolve com a criação (socialização); não tem a ver com raça. Na pesquisa a tual está em questão a combinação de formas diferenciadas de desigualdades, e nesse sentido, de fato, a homofobia se sobrepõe ao racismo. A homofobia, em outras palavras, é vivida de modo mais intenso do que o racismo ou mesmo a discriminação por classe..$^{30}$ 
31 PERLONG HER, 1993.

32 BATAILE, 1998.

${ }^{33}$ Entre outros, cf. HASENBALG, SILVA e Márcia LMA, 1999.

${ }^{34}$ Cf. MOUTINHO, 2004.
O universo pesquisa do a proxima-se de algumasdas reflexões tecidas por Perlongher, ${ }^{31}$ em especial, das que dizem respeito às questões rela tivas à territorialidade, à identidade e aos desejos que animam os mercados do prazere do sexo. Para o a utor, em vez de dissertarmossobre identidades, talvez seja conveniente falarmos de territorialidades - uma sugestão particula rmente interessante, já que o tema ora sob análise se desenrola em um espaço profundamente marcado por facções violentas, que a tuam em inúmeros territórios na cidade do Rio de Janeiro, conferindo, como dito anteriormente, contomos específicos às distinções de raça, sexualidade e gênero.

Assim, os sujeitos circulam por uma "trama" e por "redes", definindo-se a partir de sua "trajetória e posição 'topológica' na rede". O ponto da reflexão de Perlongher que interessa diretamente a esta pesquisa refere-se à maneira de se compreender os sistemas classificatórios: sã o "sinaliza dores" de intensidades libidina is, cujas muda nç a s torna $m$ visíveis (c omo, por exemplo, a s trajetórias a na lisa da sevid enc ia ra $m$ ) a lg uns dos (des)c a minhos de um desejo que "vic eja na transgressão", como sugere Georges Ba taille, ${ }^{32}$ e está em contínuo movimento, mas, igua Imente, que (re)ordena, reconfigura e por vezes obscurece as hierarquias e as desigualdades que conformam o tecido social.

Na busca por compreender a dinâmica da desigualdade social tendo sempre como pano de fundo o quadro fornecido pelos estudos demográficos e sociológicos de orientação quantitativa, ${ }^{33}$ chama a a tenção como aspectos que muitos interpretariam como restritos à esfera da sexualidade se insinuam na esfera normativa e a modificam, permitindo que se qualifiquem as muitas formas de desigualdades às qua is os ind ivíduos estão submetidos.

No caso da pesquisa sobre rela cionamentosafetivosexua is heteroc rômic os entre heterossexua is, foi interessa nte perceber como o casal homem negro/mulherbranca não somente opera com uma lógica específica de erotismo, como ta mbém reordena as representa ções correntes sobre o Brasil e o próprio processo de miscigenação, colocando em questão o lugar de dominação do homem branco, o homem modelar, bem como as assimetria s constituída s sob sua égide. ${ }^{34}$

Na pesquisa atual, o foco recai no "campo de possibilida des" que o gay ma is esc uro e ma is pobre possui - pelo menos em comparação com as mulheres e os homens heterossexuais e as travestis que ta mbém vivem em regiões empobrecidas da cidade do Rio de Janeiro.

Estudos Feministas, Florianópolis, 14(1): 103-116, janeiro-a bril/2006 113 
${ }^{35}$ SIMÕES, 2004.

Somente temos acesso ao outro pólo da díade homem negro/ma is escuro e homem branco (particularmente o estrangeiro e mais velho) a tra vés da fala dos entrevista dos, entreta nto, suas na rra tivas pa recem apontarpara uma nova "sensibilidade social", como foi destacado por Júlio Simões. ${ }^{35}$ Esta relação não foi narrada como parte de uma cena melancólica ou decadente. Não se tra ta, igua Imente, de a firma rqua lquer ma quia velismo inserido em um projeto de ascensão social, mas sim de registrar que é esse sujeito socia I quem possui um conjunto de ca ra c terístic a s rela tivas a o gênero, à cor, à orientação sexual e à classe que the permite uma chance maior de vivenciare acumularnovas e diversa sexperiências, bem como de aumentar seu capital cultural, ec onômico e social. Em outras pala vras, a a nálise das trajetórias acima apresentadas permite que se vislumbrem algumas das possibilidades de atuação de indivíduos que vivem em situação de pobreza no Rio de Janeiro.

\section{Referências bibliográ ficas}

ALVITO, Marcos. As cores de Acari. Rio de Janeiro: Editora da FGV, 2001

AZEVEDO, Thales de. Democracia racial. Petrópolis: Vozes, 1975.

BALDEШ, Débora; MOUTNHO, La ura. "Hoje eu vou me joga r!" - Indivíduo, corpo e transe ao som da música eletrônica". Olinda, Pernambuco, 2004. Paper a presentado na XXIV Reunião Brasileira de Antropologia.

BATAILE, Georges. O erotismo. Lisboa: Antígona, 1998.

BO URDIEU, Pierre. "A ilusã o biog rá fic a". In: FERREIRA, Ma rieta M.; AMADO, Jana ina (Orgs.). Usos e abusos da história oral. Rio de Janeiro: Editora FGV, 1996. p. 183-191.

BIRMAN, Patrícia. Fazer estilo, criando gênero. Rio de Ja neiro: Relume Dumará, 1995.

- "Futilidades levadas a sério: o candomblé como uma linguagem religiosa do sexo e do exótico". In: VIANNA, Hermano (Org.). Galeras cariocas: territórios de conflitos e encontros culturais. Rio de Janeiro: Ed. UFRJ, 1997. p. 227-245.

BLANC HETIE, Tha ddeus; SILVA, Ana Paula. A mistura clássic a: o a pelo do Rio de Janeiro como destino para o turismo sexual. Rio de Ja neiro: Leitura Crítica, 2004.

CECCHETTO, Fátima. Violência e estilos de masculinidade. Rio de J a neiro: Editora FGV, 2004.

DOUGLAS, Mary. Pureza e perigo. São Paulo: Perspectiva, 1996.

FERREIRA, Ma rc elo. E se o gring o for negão?: "raça", gênero e sexualidade no Rio de Janeiro - a experiência dos 
turistas negros norte-a meric anos. 2005. Disserta ção (Mestrado em Saúde Coletiva) - Programa de PósGraduação em Saúde Coletiva, Instituto de Medicina Social, Universidade do Estado do Rio de Janeiro.

FRY, Peter. Para inglês ver: identidade e política na cultura brasileira. Rio de Ja neiro: Zahar, 1982.

HASENBALG, Carlos; SILVA, Nelson do Valle; LIMA, Márcia. Cor e estratific a ção social. Rio de J a neiro: Contra Capa Livraria, 1999.

MOUTINHO, La ura. "C onsidera ções sob re violência, gênero e cor em Rio das Pedras". In: BURG OS, Marcelo (Org.). A utopia da comunidade: Rio das Pedras, uma favela carioca. Rio de Janeiro: Editora PUC-Rio; São Paulo: Edições Loyola, 2002. p. 223-249.

Razão, "cor" e desejo: uma a nálise comparativa sobre relac ionamentos a fetivo-sexua is "inter-ra ciais" no Brasil e África do Sul. São Paulo: Editora da UNESP, 2004. "Homossexualidade, core religiosida de: flerte entre o 'povo de santo' no Rio de J a neiro. In: HEILBO RN, Maria Luiza et al. (O rg.). Sexualida de, fa mília e ethos religioso. Rio de Janeiro: Garamond, 2005. p. 273-297.

NOGUEIRA, Oracy. "Preconceito racial de marca, preconceito racial de origem". In: Tanto quanto branco: estudos de relações raciais. São Paulo: T. A. Queiroz Editora, 1985. p. 67-93.

PERLONGHER, Néstor. O negócio do michê. São Paulo: Bra siliense, 1987.

"Antropologia das sociedades complexas: identidade e territorialidade, ou como estava vestida Margaret Mead". Revista Brasileira de Ciências, São Paulo: ANPOCS, ano 8, n. 22, p. 137-144, 1993.

PISC ITEШ, Adriana. Visões imperiais: gênero e sexualidade no contexto do turismo sexual internacional em Fortaleza. Washing ton DC, 2001. Papera presenta do no Meeting of the Latin American Studies Association.

"Entre a praia de Iracema e a União Européia: turismo sexual intemacional e migração feminina". In: PISC ITEШ, Adria na; GREG O RI, Ma ria Filomena; CARRARA, Sérgio (Orgs.). Sexualidade e saberes: convenções e fronteiras. Rio de J a neiro: Ga ramond, 2004. p. 283-318.

SILVA, Nelson do Valle; HASENBALG, Carlos. Relações racia is no Brasil contemporâneo. Rio de Janeiro: Rio Fundo Ed itora/IUPERJ , 1992.

SIMÕES, Julio Assis. "Homossexualidade masculina e curso de vida: pensando idades e identidades sexua is". PISC ITEШ, Adriana; GREG ORI, Ma ria Filomena; CARRARA, Sérgio (Orgs.). Sexualidade e saberes: convenções e fronteiras. Rio de J a neiro: Garamond, 2004. p. 415-447. 
STO LC KE, Verena. "Sexo está pa ra gênero, a ssim como raça pa ra etnic ida de?". Revista Estud os Afro-Asiátic os, n. 20, p. 101-119, 1991.

TEIXEIRA, Maria Lina Leão. Transas de um povo santo: um estudo sobre identida des sexua is. 1986. Dissertação de Mestra do - Programa de Pós-Gra dua ção em Sociologia e Antropologia, Universida de Federal do Rio de J a neiro.

VELHO, Gilberto. Projeto e metamorfose: antropologia das sociedades complexas. Rio de Janeiro: Jorge Zahar Ed itores, 1994.

ZALUAR, Alba. Condomínio do Diabo. Rio de Janeiro: Ed. Revan/Ed. UFRJ, 1994.

"Apresentação - violência, cultura e poder". In: CECCHETTO, Fátima. Violência e estilos de masculinidade. Rio de Janeiro: Editora FGV, 2004.

[Recebido em dezembro de 2005 e aceito para publicação em abril de 2006]

\begin{abstract}
Negotiating with Adversity: Discussion on "Race", (Homo)Sexuality and Social Inequality in Rio de Janeiro

Abstract: The a im of this artic le is to disc uss how the affection and pleasure dynamic intersect with the social inequality in the gay and lesbian circuit in Rio de Janeiro city. Part of the life trajectory of two young black homosexuals living in the carioca suburbs, and one living in Maré slum, will be more partic ularly approached. The field work emphasized that, in this context, the darker male homosexuals living in suburbs and slums in Rio de J aneiro have a broader range of action than those in which young heterosexual male and female and even lesbians and transvestites of different color living in these areas are inserted.
\end{abstract}

Key Words: Homosexuality, Poverty, Race/Color, Rio de J aneiro, Affective/Sexual Interracial Relations, Social Inequality. 